\title{
A VIOLÊNCIA DOS JUSTOS: EVANGÉLICOS, MÍDIA E PERIFERIAS DA METRÓPOLE*
}

\section{Patricia Birman Carly Machado}

\section{Introdução}

Foi assistindo a um de seus vídeos postados no youtube que o pastor Marcos Pereira, da Assembleia de Deus dos Últimos Dias (ADUD), despertou a nossa atenção. $\mathrm{O}$ vídeo trata de um assunto candente que facilmente ocupa as primeiras páginas de jornais populares: uma expedição de resgate de um jovem ameaçado de execução pelo chamado tribunal do tráfico, isto é, um grupo de traficantes de drogas que castiga e/ou mata supostos traidores em lugares da periferia sob seu "controle". Nosso

* A primeira versão deste texto foi apresentada no Seminário "Deus, diabo e outras pessoas: reflexões sobre o cristianismo na floresta e na cidade", organizado por Aparecida Vilaça, em 2010 no Museu Nacional. Agradecemos à organizadora e a todos os colegas presentes pelos seus comentários e sugestōes.

Artigo recebido em 19/06/2011

Aprovado em 27/04/2012 interesse aqui é analisar como esse universo social de morte e violência submete-se a uma leitura evangélica promovida pela igreja Assembleia de Deus dos Últimos Dias.

Lembramos que a violência foi construída como um problema urbano complexo há pouco mais de duas décadas, construção que envolve uma série de pesquisadores e situações a respeito das quais não trataremos aqui. ${ }^{1}$ É importante considerar, porém, que as interpretações e significados atribuídos à violência durante este período geralmente tiveram atores religiosos como protagonistas.

$O$ vídeo baseia-se na concepção religiosa da ADUD a respeito de territórios à margem e da relação da população com a criminalidade. A narrativa enfatiza uma ação específica, qual seja, o ato de salvar alguém de uma morte certa, sugerindo dramaticamente ao espectador os vários sentidos que este resgate salvador engloba. De fato, seus sentidos não se atêm somente ao plano propriamente religioso, 
mas se estendem a outras dimensões da vida social. O jovem resgatado do tribunal do tráfico teria sido salvo pelo pastor de várias condenaçôes interligadas e sobrepostas, como por exemplo a morte física, a marginalidade e seus efeitos sociais e morais e, finalmente, como pecador, a perda da vida eterna. Ampliam-se, assim, os sentidos atribuídos ao trabalho missionário desta igreja, destacando-se o conjunto de aspectos envolvidos em seu projeto religioso em ação (social, político e moral). Com efeito, as atividades rituais do pastor Marcos Pereira, pastor-presidente desta igreja, convida-nos a pensar sobre o protagonismo político-religioso reclamado pelas novas igrejas evangélicas no Brasil.

As igrejas evangélicas, segundo certo consenso consolidado entre os especialistas, renovaram a participação religiosa no espaço público e colocam em risco a hegemonia católica, principalmente nos grandes centros urbanos. Diversos estudiosos destacaram ainda que o crescimento evangélico não acarretou um "desencantamento" do mundo, eliminando a magia das mediações sagradas. Este aspecto, como se sabe, integra a tradição católica brasileira. O que foi decretado morto pelo protestantismo, isto é, o povoamento do mundo por mediadores diversos, é recuperado de outra forma pelas igrejas pentecostais renovadas. A igreja do pastor Marcos Pereira faz milagres e santifica seus meios de ação, como aliás muitas outras que tanto exaltam o poder do Espírito Santo no mundo. Há, portanto, uma afirmação cotidiana de uma intervenção divina através de milagres que está muito longe do ascetismo protestante e do prognóstico de "desencantamento do mundo", previsto pela sociologia com o advento do protestantismo e da modernidade. $^{2}$

Com efeito, a multiplicação de igrejas evangélicas tem sido acompanhada por um aumento dos circuitos religiosos disponíveis. ${ }^{3} \mathrm{O}$ mundo da política e da cultura ganhou dispositivos que integram uma interface evangélica, cuja forma de ação é indissociável de projetos políticos considerados seculares. Pretendemos explorar as atividades desta igreja em dois aspectos: o primeiro concerne às modalidades de intervenção que realiza no plano ritual, cujo caráter inovador revela uma peculiaridade do evangelismo que hoje cresce entre nós, a saber, a va- lorização e a santificação de inúmeros mediadores humanos, materiais e imateriais em suas práticas; o segundo diz respeito à especificidade de seu projeto, ao mesmo tempo teológico, político e social, que participa de dispositivos político-religiosos relacionados com o tratamento da violência na cidade. Esta igreja constrói uma percepção evangélica dos territórios à margem ${ }^{4}$ do Estado e da população, bem como põe em prática soluções cristãs como instrumentos complementares (e também em oposição) de outras formas seculares de intervenção. De um lado, as ações rituais, extremamente elaboradas, participam da construção desses territórios como uma região moral (Park, 1973) a ser salva pela conversão de seus integrantes a uma comunidade de fiéis; de outro, integram a construção do carisma e da legitimidade política, social e moral de seus pastores, que reclamam uma maior participação na condução dessas populações.

\section{Imagens, missão e transmissão}

A relação do pentecostalismo com as mais diversas mídias e tecnologias chama atenção no campo de pesquisa dos estudos da religião, mas é, em geral, tomada como um dado acessório na descrição etnográfica. O caso específico que pretendemos analisar neste artigo implica uma reflexão sobre a mídia, especificamente os vídeos produzidos por esta comunidade religiosa da Baixada Fluminense do Rio de Janeiro, não como via de exibição de suas práticas, mas como canal santificado de transmissão de seus projetos e de sua missão. ${ }^{5}$

Liderada pelo pastor Marcos Pereira, a ADUD tem como prática fundamental a filmagem e a edição de suas açôes rituais e missionárias. É conhecida e reconhecida como um centro cujas práticas religiosas empregam uma grande produção e circulação de imagens. Seus vídeos são produzidos e transmitidos em todos os espaços de sua atuação igreja, prisões, favelas, ${ }^{6}$ delegacias e periferias -, tornando-se, assim, um canal investido de poder religioso e secular direcionado às intervenções da igreja a um só tempo religiosas, sociais e políticas. A relação com a imagem, como se sabe, constitui um importante eixo das práticas religiosas. Esta relação 
carrega uma série de tensões com os ídolos e santos, atravessando, desse modo, as elaborações do cristianismo com a transcendência e, como poderíamos esperar, ela também integra as reflexões da ADUD sobre o uso de imagens. A recusa e a denúncia da idolatria, balizas históricas do protestantismo, são submetidas a uma perspectiva teológica de revalorização da imagem. Para lidar com este possível paradoxo, o pentecostalismo midiático da ADUD faz um esforço no sentido de distinguir imagens mortas de imagens vivas. Estas últimas seriam mediadores positivos para o contato com o Espírito Santo, assim como os corpos das pessoas vivas:

A Bíblia relata que quando Deus criou os céus e a terra, não os criou para ficarem vazios, mas sim para que fossem habitados (Isaías cap. 45 vers. 18), ou seja, tudo que Deus fez é um templo de vida. A cópia de um ser criado por Deus torna-se morada de espíritos imundos, ministradores do mal, trazendo grandes malefícios, tais como: dissensões no lar, enfermidades, improsperidade e etc. Isto se deve ao fato de que podemos copiar, mas não temos poder de dar a vida (Disponível no site da ADUD).

Em contraposição ao postulado doutrinário da ADUD, que recomenda "não ter imagens", sua prática legitima as imagens vivas em dois sentidos - vivas por representarem pessoas vivas e resgatadas da morte, mas também por não serem imóveis. $\mathrm{Na}$ crítica protestante ao catolicismo, ídolos são entes mortos. ${ }^{7}$ Os vídeos da ADUD, frisa o pastor, apresentam imagens em movimento. ${ }^{8}$ A rejeição à idolatria ao lado da proliferação de imagens no templo da igreja nos impõe, assim, um esforço analítico.

Vida e morte são categorias centrais para a demarcação do agenciamento das imagens na experiência pentecostal da ADUD. A igreja não cria imagens, mas transmite imagens vivas criadas por Deus. Sua produção é, portanto, uma ponte santificada para a comunicação do poder do Deus vivo. Reforça-se uma concepção da morte em oposição direta à possibilidade redentora de um sofrimento "vivo". Se os santos e a idolatria guardam uma relação com a morte ${ }^{9}$ - afinal uma pessoa só se torna santa depois de morta -, no contexto pentecostal a santificação é uma ação em vida e pela vida, que reconhece a agência presente em vários objetos. $\mathrm{O}$ mesmo acontece com as imagens: as inertes, "sem vida”, são consideradas imagens sem agência, e seu culto revela o pecado da idolatria; as vivas, em movimento, permitem a presença de agentes da salvação, por intermédio dos quais circula o poder do Espírito Santo ${ }^{10}$ : "Tudo que Deus fez é um templo de vida". As imagens e o corpo do pastor em ação possuem o poder de redimir os indivíduos do jugo da violência, do suplício e da morte. $\mathrm{O}$ exorcismo que o pastor praticou em prisões foi integrado, durante algum tempo, à gestão dos encarcerados no governo Garotinho. ${ }^{11}$

Sediada no município de São João de Meriti na Baixada Fluminense, a ADUD realiza, além de seus cultos dentro do templo da igreja, um conjunto de ações em espaços exteriores, principalmente no interior de favelas e das periferias em geral. Como veremos adiante, a articulação entre esses espaços rituais dentro e fora da igreja é efetivada pela mediação audiovisual.

Territórios, pessoas e identidades formam um conjunto em analogia à comunidade de fiéis. As relações entre os espaços internos e externos são ritualmente trabalhadas para produzir e reiterar tal analogia, aproximando o mundo dos vivos àquele da redenção, do pecado e da morte. Ora, é espantosa a articulação entre tempos e espaços diversos realizada pelos vídeos da ADUD e concretizada em momentos rituais expressivos dos cultos. As imagens produzidas pela igreja abrangem preferencialmente dois campos: dentro da igreja são registradas imagens da vida; no mundo, imagens da morte. No dia a dia, esses vídeos se articulam para forjar as relações da comunidade de fiéis com o seu passado e os seus lugares de origem.

O salão da ADUD, frequentemente usado como "locação", comporta em torno de setecentas pessoas sentadas, e a ocupação do espaço obedece a uma divisão de gêneros e de poder: mulheres de um lado, homens de outro, dirigentes e celebridades no púlpito, cuja parede ao fundo é adornada com a imagem do pastor Marcos e sua filha. ${ }^{12}$ Espalhadas por todo o salão, encontram-se telas de TV emitindo imagens com a marca ADUD Produções, cuja ilha de transmissão localiza-se ao fundo do templo. 
Câmeras gravam e transmitem simultaneamente nas telas todos os eventos. ${ }^{13}$ Essa estrutura ritual que combina elementos mobiliários, tecnológicos, imagéticos e humanos possibilita que se conjuguem e se façam presentes ali outros tempos e espaços.

A igreja é frequentada por muitos homens, a maioria deles resgatados da morte. A comunidade de fiéis integra o mundo do crime como seu "outro" sempre presente e cotidianamente evocado. Ao longo do culto, as telas frequentemente transmitem imagens divididas em duas metades: de um lado, o vídeo do passado dos fiéis ali presentes,enraivecidos, de metralhadoras em punho, roupas em farrapos em ambientes sombrios; de outro, imagens "ao vivo", em tempo real quando os fiéis se veem projetados na tela enquanto oram e louvam. Isso torna o culto um acontecimento tridimensional, pois ali estão presentes o lugar do passado, o presente na tela (virtual) e o que acontece no momento (real).

$\mathrm{O}$ encapsulamento espaço-temporal que assim se efetua provoca, como experiência compartilhada, um sentimento de atemporalidade. Por instantes suspendem-se as referências estáveis de cada um para engendrar o pertencimento a uma comunidade unida pelo Espírito Santo. Momento identitário forte que em parte será dissolvido em seus efeitos totalizantes ao final do culto.

A conjugação de elementos habitualmente mantidos em separado, tanto na esfera social como nos âmbitos moral e religioso, pode ser valorizada como forma de elaborar um momento de liminaridade - suspensão do tempo e do espaço que dá lugar a uma explosão de sentimentos de êxtase que reafirmam o compartilhamento emocional e espiritual dos presentes. ${ }^{14} \mathrm{~A}$ totalidade forjada pelos eventos da ADUD - sua filmagem, edição e transmissão nas mais diversas mídias - constitui, assim, o conjunto ritual que marca a prática desta igreja. Ali não se adoram imagens, mas a igreja se reproduz através de imagens. Imagens no gerúndio, continuamente se produzindo e reproduzindo.

Em certa ocasião, o pastor Marcos, referindo-se a uma ação de invasãa ${ }^{15}$ de um baile funk, contou à congregação que foi chamado para pregar o evangelho nesse ambiente. ${ }^{16}$ No culto, ele pediu que se exibisse o vídeo da invasão, ${ }^{17}$ com imagens do baile editadas em ritmo acelerado e fragmentado ao som de música funk em volume elevado. Assim, o pastor Marcos "invade" o baile, e o baile "invade" a igreja.

Destacando o gênero performativo dos eventos de liminaridade, Turner aponta apropriadamente para o fato de as performances culturais serem compostas por mídias culturais (cultural media).$^{18}$ Dentro da igreja, o caminho do pecado à redenção se apresenta em parte como um roteiro que se concretiza nos vídeos assistidos. $\mathrm{Na}$ audiência, dispõem-se lado a lado os participantes do culto e os protagonistas dos vídeos dos resgate que, juntos, partilham da esperança de redenção apresentada passo a passo nos vídeos.

Um dos principais os objetivos missionários da ADUD é transformar os indivíduos, designados como resgatados da morte, em uma categoria especial de fiéis, que protagonizam nos vídeos suas próprias histórias de vida, arranjadas evidentemente por critérios e da perspectiva da igreja. As histórias testemunham suas experiências com a morte, com o sofrimento e com os territórios onde estiveram reclusos: esconderijos do tráfico, celas de delegacias e penitenciárias. Através de seus corpos marcados e transformados pelo sofrimento, os ex-bandidos e ex-traficantes ${ }^{19}$ operam como mediadores sociais para a formação de uma nova comunidade de salvação, em oposição à vida que deixaram para trás. ${ }^{20}$ Terminado o ritual, o passado e o pecado ficam confinados às imagens na tela, enquanto o presente e a redenção circulam livremente na igreja.

\section{A missão do pastor: construção de tempos, espaços e fronteiras}

A narrativa da ADUD sobre sua própria história toma como marco inicial as açôes do pastor Marcos no presídio da Ilha Grande, na década de 1990, o que é revelador da maneira pela qual ele se concebe como alguém cujo mandato divino leva a desenvolver práticas religiosas que não só ajudariam o Estado a lidar com as populações marginais, mas também a corrigir suas falhas: ele busca agir onde o Estado se mostraria incapaz de impor sua ordem. Forja-se através desses vídeos nas ruas da cidade uma topografia da violência no Rio de Janei- 
ro. Destacando as cenas de enfrentamento do chamado tribunal do tráfico, a ação pastoral de Marcos Pereira privilegia os espaços vinculados à violência e, dentro deles, os ditos bandidos em situações de confronto. ${ }^{21} \mathrm{~A}$ intervenção missionária e salvadora do pastor pretende resgatar ambos os "lados" envolvidos: vítimas e agressores. Dos dois lados desse confronto, e espalhados em seus territórios, estão aqueles que ao Estado, segundo o pastor, não interessa salvar e que, frequentemente, condena ao extermínio. Referindo-se a esse tipo específico de pastorado, um pregador, prestando homenagem ao pastor Marcos, afirmou: "ao invés de pensar - é só mais um drogado, deixa morrer - o Pastor vê a ovelha sangrando e diz - é minha - e eu luto pelo que é meu. Pode não valer nada para a sociedade, mas para mim vale”.

Ele se dedica a pessoas, acompanhando aqui as referências conceituais de Giorgio Agamben (2008), cujas mortes difícil e raramente são tratadas como homicídios, com a punição de seus responsáveis. ${ }^{22}$ A câmera da igreja nos conduz justamente até eles; por meio de suas imagens chegamos ao interior de uma das numerosas periferias da metrópole do Rio de Janeiro, onde cenas violentas são interrompidas pela palavra e gestos triunfantes e eficazes do pastor. $\mathrm{O}$ espectador entra, assim, em uma reunião do tribunal do tráfico, onde os ditos traficantes são interrompidos pelo pastor no ato de maltratar, torturar e punir seus inimigos. Imagens desfocadas de maus-tratos físicos, ameaças de morte, gritos e súplicas são exibidas aos espectadores do interior esconderijo que aprisiona suas vítimas, posteriormente libertadas pelo pastor.

Sua missão no campo pentecostal, que lhe possibilitou construir perfil da ADUD e garantiu seu reconhecimento como pastor, desenvolveu-se, como mencionamos, voltada a um conjunto espacial e social específico: prisões, penitenciárias, delegacias, favelas e regióes periféricas. Esses espaços perfazem um conjunto coerente do ponto de vista teológico e missionário. Seriam todos dominados pelo crime, por forças diabólicas e pelo pecado. Porém possuem outro elemento em comum, qual seja, o vínculo entre sofrimento e aprisionamento. Todos fazem parte de um continuum, cujos limites e fronteiras são indefinidos: a favela, o baile funk, o esconderijo do tráfico, as delegacias e as prisões. $\mathrm{O}$ crime, a violência e o pecado os definem ao mesmo tempo pela exclusão da cidade e pelo confinamento de população em suas fronteiras externas à cidade e à salvação. Trata-se, acompanhando Michel Foucault, de espaços "heterotópicos": "Espaços capazes de justapor em só lugar real vários lugares, vários posicionamentos incompatíveis". ${ }^{23}$ Emerge, assim, a produção cotidiana de uma população de indesejáveis, ${ }^{24}$ submetida a formas específicas de exclusão e inclusão.

A maioria dos filmes produzidos pela ADUD conduz, portanto, os espectadores a uma viagem ao encontro do mal com o intuito de salvar os que lá se encontram da morte física, social e espiritual. Rebeliōes em presídios, superlotação de delegacias, situações de sequestro e territórios sob ameaça de ataques armados, tudo isso poderia ser evitado pela intervenção do pastor. As narrativas enfatizam, pois, a eficácia de sua ação religiosa, decorrente do fato de ele ser um excelente, ou mesmo excepcional, mediador da ação divina e transcendente do Espírito Santo no mundo. ${ }^{25}$

Avancemos algumas reflexões sobre as formas de articulação pentecostal do corpo (na sua relação com a força, com o sofrimento e com o poder que constituem o perfil do fiel dessa igreja), do tempo (pela exploração de temporalidades diversas relacionadas simultaneamente com experiências de morte e de redenção) e do espaço (na forma de construir uma comunidade moral entre o real e o virtual, o imanente e o transcendente, planos utópicos e heterotópicos).

\section{Da força dos homens ao poder pastoral}

O pastor Marcos chama a atenção pela radicalidade com que "embebe" suas atividades religiosas de dimensões mundanas, com destaque para aquelas que afirma combater. ${ }^{26}$ Diferentes autores já assinalaram o quanto os pentecostalismos contemporâneos transformam em instrumento de cura e de redenção mediadores considerados "diabólicos", como objetos, imagens e pessoas. ${ }^{27}$ No caso do Brasil, os mediadores privilegiados explicitamente por certas igrejas e valorizados pelos 
pesquisadores provêm das religióes consideradas "tradicionais". 28

O essencial nos escaparia se fôssemos buscar somente referências a religiosidades tradicionais no uso que a ADUD faz desses mediadores. Isso não quer dizer que tais referências não existam, mas simplesmente que a matéria-prima de sua ação pastoral destaca principalmente mediadores classificados como "seculares" na vida social. A violência física e moral que acompanha em detalhe o curso da vida desses indivíduos nas periferias urbanas é tomada como parte constitutiva e necessária à ação mediadora do pastor, uma vez que se trata de algo inseparável da vida dos fiéis. Objetos associados a estas vidas são transformados em meios rituais: imagens, estigmas e diversos instrumentos que participam da produção da violência.

Tanto a população alvo do trabalho missionário como o próprio pastor carregam experiências fortes de coação física e social presentes nesses e em outros territórios. Sua ação é valorizada nos programas de televisão e em vídeos como particularmente benéfica para os moradores de um território considerado violento e, ao mesmo tempo, objeto de violência por parte do Estado. São designados hegemonicamente como integrantes de uma "região moral”, na qual a linguagem da força seria a regra.

Neste cenário de crime e redenção, a violência tematizada não é somente aquela que atinge vítimas "legítimas" (as que sofrem os efeitos do crime, sem nunca cometê-lo), mas também a que recai sobre seus algozes. Estes, quando redimidos, mobilizam suas experiências relativas à violência sofrida e praticada no mundo do crime e em situações de encarceramento. ${ }^{29}$ Se o sofrimento social ${ }^{30}$ tende a desencadear nas políticas públicas a promoção do cuidado dos pobres, a condição de bandido pobre não é acolhida facilmente. A ADUD afirma que todos somos e fomos (de alguma forma) criminosos. Tal via identitária e doutrinária possibilita no sentido ético o reconhecimento e a acolhida dos bandidos.

O sofrimento como instrumento religioso de compartilhamento de uma mesma identidade pode ajudar a compreender como o pastor Marcos "relativiza" a crueldade. Não que ele seja "conivente com o crime", como habitualmente reagem os que o acusam, mas ele afirma com insistência que a crueldade estaria presente nos "dois lados": aqueles que agem de forma cruel são também alvo da maldade alheia. ${ }^{31}$ Segundo o pastor, seriam ao mesmo tempo vítimas e algozes, incapazes de eliminar o sofrimento que tanto impóem como recebem de seus inimigos. Essa ideia decorre de uma premissa teológica, qual seja, a vida no mundo, como um lugar baixo e diabolicamente determinado, é atravessada por movimentos de coação e por conflitos violentos sem que haja na sociedade uma fonte moral confiável com a qual seria possível contar. ${ }^{32}$

Para ilustrar essa percepção generalizada nada melhor do que o aforismo evangélico que define o mundo como um lugar mau e pouco habitável. Nega-se a existência de uma contrapartida humana capaz de vencer o império do mal que o conforma. Escrito em muros, colados em carros, táxis e caminhôes, encontramos o lema: "Tudo é força, mas só Deus é poder".

Com efeito, o pastor Marcos se apresenta como aquele que é capaz de realizar o milagre cotidiano de transformar a força em poder. As relações sociais marcadas pela violência só podem ser modificadas, na visão evangélica, por uma potência sobre-humana, divina. Essa potência maior, segundo o missionário, apoia-se nos indivíduos que testemunham suas experiências físicas e morais de coação. Ao serem postas a serviço de Deus, tais experiências se convertem em instrumentos libertadores, investidas que foram pelo sopro do Espírito Santo.

A força, exibida regularmente em noticiários sobre favelas e violência e configurada em corpos viris de jovens armados, é então submetida à verdade cosmológica contida naquele aforismo. O pastor Marcos encarna o ideal religioso de sua igreja, transformando sua força física e seu passado no pecado, inscritos no seu corpo viril em poder de intervenção divina.

Tem sido por meio de imagens de corpos mutilados que a mídia secular descreve o caráter abjeto da morte (merecida, dizem muitos) não só dos inimigos da sociedade - traficantes e bandidos -, mas também daqueles identificados na mesma região moral. Os corpos mutilados ajudam o pastor a demonstrar o poder incomensurável do sacrifício cristão para redimi-los. Há certamente um diálogo implícito e altamente eficaz entre as 
mídias secular e religiosa. ${ }^{33}$ Enquanto a primeira frequentemente explora na cena pública a visibilidade desses corpos para reafirmar a legitimidade de uma política do Estado que dispóe da vida e da morte dos moradores desses territórios, a mídia religiosa destaca a necessidade imperiosa de salvá-los da morte física e redimi-los como filhos de Deus. ${ }^{34}$ A igreja participa, a seu modo, dos dispositivos de criminalização das populações pobres: afirmar o crime e seus locais de ocorrência valoriza os empreendimentos de salvação.

De fato, existe uma diferença política e moral em relação à exibição escandalosa do extermínio de jovens pobres e negros das periferias urbanas. Se a orientação política predominante no espaço público busca invisibilizar o que neles a morte violenta quis desfazer - a condição de pessoa -, os recursos mediáticos do pastor são postos a serviço de sua salvação pelo reconhecimento cristão de uma humanidade em comum..$^{35}$

A mensagem da ADUD atravessa o "vale dos ossos", como afirma a canção Receba vida, de Nívea Silva, filha do pastor Marcos. Diz sua profecia que neste vale, onde não há mais nada, apenas a morte, o profeta vai juntar os ossos, que criarão carne e neles crescerão nervos. "Em nome de Jesus a morte vai embora", é o que profetiza a cantora em hospitais e prisões. As pessoas ali presentes são simbólica e socialmente consideradas mortas, e lhes é ofertada pela igreja a oportunidade de nascer de novo.

Esses corpos representam também o destino quase evidente daqueles que seriam os responsáveis maiores pela violência na cidade. A ação evangélica, ao contrário da perspectiva secular, não acompanha a corrente hegemônica que desfaz as conexões desses indivíduos com a vida social. Busca, ao contrário, redimi-los e reconsiderá-los, tendo por base sua condição de seres humanos, filhos de Deus. Enquanto a morte é o fim da linha e o corpo morto e mutilado é a evidência do resultado da vida em pecado, o sofrimento é uma via aberta à redenção. $\mathrm{O}$ corpo machucado, ferido, porém vivo e sofredor é um símbolo de redenção, da libertação da morte e, por meio do sofrimento, da libertação do pecado. O sofrimento faz do resgatado da morte um símbolo vivo do poder de Deus e de seus mediadores. Contrariar a força do tráfico, vencê- -la, derrotá-la no seu próprio terreno é, pois, apresentado como um ato exemplar do infinito poder divino. Em situações extremas como estas, pode-se ver que o extraordinário acontece: a força se dobra ao poder. Redimir os ditos bandidos, contudo, não é destituí-los dessa corporalidade associada à masculinidade, ao sofrimento e ao crime, mas significa sobretudo redirecionar seus atributos físicos para o sentido moral que, momentaneamente, deles se ausentou. Ligar a força ao poder é também ligar o corpo ao Espírito e os homens pecadores/marginais/ criminosos a Deus e à sociedade. Como afirma a divisa: "Resgatando vidas, restituindo cidadania e promovendo a inclusão social". ${ }^{36}$

Os atributos pessoais do pastor, de fato, estão longe da realização de um projeto de espiritualização da sua pessoa por meio de uma crescente desconexão corporal com o mundo e sua imanência. Ao contrário, como personagem de sucesso mediático, ele sempre põe em relevo a virilidade que comanda a ação do seu corpo como parte integrante da sua atividade missionária e como efeito do seu contato com o Espírito Santo. A linguagem do amor, como já vimos se manifestar em momentos de compartilhamento em outras comunidades pentecostais, cede terreno a sentimentos menos delicados. A relação do pastor com o Espírito Santo não o faz beneficiário de um fluxo divino que se revelaria essencialmente por sentimentos de preenchimento físico e espiritual, capazes de provê-lo de alegria, amor, pureza e santidade. A experiência do êxtase parece se realizar através de sentimentos e sensaçóes que, ao contrário desses, se alimentam da vitória sobre o poder de coação usado pelo demônio, em relação estreita ao uso da força física.

Os vídeos em que o pastor pratica o exorcismo oferecem aos espectadores uma outra economia de sentimentos. Outra ênfase nas emoçôes parece se impor às cenas rituais: menos comoção e mais determinação, menos enlevo e mais desejo de triunfo, menos gozo interior e mais vontade de derrotar e esmagar os inimigos de Deus. O Espírito Santo, neste caso, não "libera" o pastor do seu corpo, mas o instrumentaliza como matéria-prima essencial, responsável pela força física e por sua imagem que, com o auxílio de Deus, se transforma em poder. 


\section{Da ação violenta ao corpo salvo e redimido}

A libertação dos indivíduos sugere, é claro, uma transformação redentora. Esta faz do sacrifício corporal, segundo a imagem do sacrifício de Cristo, a condição necessária para transformar a pessoa em instrumento abençoado do Senhor. Tal sacrifício insiste sobre o sofrimento fisicamente imposto pelos bandidos aos que se encontram sob seu poder. A libertação promove, assim, um renascimento que guarda as marcas de sua origem. Ex-bandidos libertam-se dos sofrimentos vividos, e também dos sofrimentos provocados, mas sem "apagá-los" por completo, pois a memória também alimenta seu poder espiritual: "Onde abundou o pecado, superabunda a graça", afirmam reiteradamente os evangélicos.

Com efeito, tanto em seus filmes como ao vivo na igreja e nos lugares em que pratica o exorcismo, o pastor realiza um conjunto de gestos que mimetiza a prática da violência: barulho de metralhadoras, gritos, exclamações e ordens imperativas. Levanta as mãos como se fossem revólveres que miram pessoas endemoniadas. A ação violenta do pastor derrota e humilha corpos possuídos pelo diabo. As pessoas diante das câmeras e do público caem inertes quando recebem emanaçōes sonoras das metralhadoras provenientes de seus gestos e aliteraçôes, frequentemente misturados com manifestações de glossolalia. Falar línguas estranhas, habitual nos templos pentecostais, aqui se entrelaça com o mimetismo sonoro e gestual com o qual o pastor reproduz o efeito dos tiros. Esses gestos e sons conjugados engendram efeitos previsíveis: a queda, o desmaio, a imobilidade corporal. A morte ritual encerra-se quando o pastor ordena às pessoas se reerguerem sob os aplausos, aleluias e glórias bradados pelos fiéis.

A performance do pastor não está dissociada daqueles gestos descritos no início deste artigo sobre o vídeo onde aparece o flagrante seguido da libertação da vítima, no esconderijo dos bandidos. Indicamos, primeiramente, as circunstâncias em que o pastor interveio: em um lugar ermo, "fora" da cidade, um "espaço heterotópico", onde bandidos supliciam com violência indivíduos impossibilitados de reagir. A ação do pastor é duplamente redentora: ali, nos redutos obscuros do crime, ele age ritualmente como se estivesse na igreja, imobilizando os bandidos por meio da palavra divina e salvando almas em corpos ainda vivos apesar de socialmente mortos. Estaríamos diante de atos que rejeitam o tratamento dos indivíduos como traste, lixo inútil e anônimo, como ocorre cotidianamente no Rio de Janeiro, onde se convive em silêncio com cemitérios clandestinos e mortes sem corpos a serem enterrados, ou corpos desfigurados sem identificação possível. A intervenção do pastor salvou almas e transformou o sangue derramado em sacrifício que redimiu os pecadores, ganhando-os para a vida em sociedade.

Essa poderosa metáfora do cristianismo abarca o sangue derramado dos bandidos como via de redenção. Os inúmeros vídeos sobre os Resgatados da morte exibem imagens da transformação pela qual passaram os indivíduos. $\mathrm{O}$ contraste entre a postura e a vestimenta de início e nas últimas cenas é recorrente: pessoas seminuas num ambiente violento aparecem ao final vestidas com o uniforme pentecostal por excelência - terno, gravata e Bíblia em mãos. Interligam-se, pois, os signos de salvação e de integração social.

Os testemunhos de conversão ressaltam frequentemente o grande contraste entre o "antes" e o "depois". São os ex-bandidos, ex-assassinos os mais capacitados a dobrar com sua força/poder os inimigos de Deus. Personagens públicos, eles trazem para a cena religiosa a experiência vivida de pertencimento a dois mundos, ainda que em tempos e espaços diferenciados, que não deixam, contudo, de se articular. Aprenderam a empregar a força física como meio de coação e sobreviveram quando esta se voltou contra eles. $\mathrm{Na}$ igreja aprenderam a usá-la como instrumento de salvação. É da articulação entre esses espaços, tempos, pessoas e experiências que se cria a comunidade de fiéis como um espelho da região moral à qual "eles" são assimilados e da qual são testemunhos.

\section{Comunidade moral e identificação de seus lugares}

O breve relato sobre os filmes produzidos na ADUD nos convida a analisar os discursos, ain- 
da pouco estudados, sobre o modo evangélico de pensar e de atuar na metrópole. ${ }^{37}$ Como mencionamos, a metrópole é vista a partir de suas margens e dos espaços concebidos como heterotópicos. Estas margens são enunciadas como referências espaciais por intermédio de lugares emblemáticos que condensariam os sentidos de exclusão e de confinamento presentes nesses territórios. Em vez da sede da paróquia, ou das igrejas localizadas em bairros, ou mesmo de locais públicos, os discursos religiosos proferidos do púlpito da igreja fazem das delegacias de polícia os primeiros pontos de referência para identificar os lugares de pertencimento de seus fiéis. ${ }^{38}$ Pedem-se bênçãos e proteção às favelas e às comunidades referidas pelo trabalho da igreja. As oraçôes também percorrem as ruas da vizinhança da igreja e chegam às casas de alguns fiéis. Das delegacias, as oraçôes voltam-se para o espaço institucional da igreja, que abriga os resgatados da morte.

Com diferentes estratégias, os líderes da ADUD integram, portanto, os ex-bandidos à comunidade mais ampla dos que se encontram em territórios periféricos, classificando a população nas topografias variadas da exclusão. Constroem-se, pois, momentos de identificação coletiva, cujos critérios permitem valorizar os ex-bandidos e abarcar seus próximos, definidos das mais diversas maneiras - vizinhos, parentes, amigos, companheiros de prisão e do tráfico. É no entanto a categoria de pecadores que os implica na mesma comunidade moral. $O$ valor do preso é uma expressão correntemente utilizada pelos líderes da igreja em suas pregaçōes: "do seu lado pode ter alguém que saiu do presídio e você não reconhece. Levanta a mão e dá glória!"

A categoria jurídica crime ganha outro sentido ao ser vinculada à noção de pecado: "Todos já cometeram algum pecado, algum crime. Não há diferença entre roubar uma caneta e assaltar um banco". Levando ao extremo a ideia presente no meio evangélico de que "não há pecadinho nem pecadão", a mensagem da ADUD é de que todos fomos pecadores e criminosos, mas agora seríamos criminosos redimidos; além disso, continua o lema: "todos estamos presos por alguma coisa". O jogo de equivalência entre tais categorias deu lugar a uma expressão jurídico-política-espiritual. Grande parte dos membros dessa comunidade precisou de um alvará para sair da prisão. No entanto, mesmo fora da cadeia, todos esperam pelo seu alvará espiritual.

\section{Consideraçôes finais}

Fronteiras, imagens e mediação são elementos constitutivos de um fazer religioso orientado para o combate à violência e à morte em espaços periféricos, onde habitam os indesejáveis da cidade.

Insistimos que as fronteiras aqui referidas não são entendidas pela Assembleia de Deus dos Últimos Dias como simplesmente físicas e territoriais ou meramente "simbólicas" e sociais. Trata-se de um combate no interior de um espaço que, como descrevemos, é considerado lócus da violência, e que só pode ser liberto por intermédio de uma ação que transcenda a sua natureza terrena, humana e social. Em outras palavras, esta igreja, mediante sua ação pastoral, empenha-se em criar fronteiras qualitativamente distintas. Sua intenção é construir outra comunidade, uma comunidade imaginada nos termos de Benedict Anderson, que podemos designar também como comunidade virtual, fruto de um trabalho profético e em oposição àquela em que a morte e o sofrimento convivem no cotidiano dos habitantes da cidade. A libertação dos indivíduos de uma comunidade e o ingresso na outra é o objetivo perseguido pela ADUD.

Para alcançar sua finalidade missionária, os meios que emprega tampouco são humanos, ou melhor, são meios humanos revestidos de uma qualidade outra, aquela proveniente do poder divino. É preciso insistir neste aspecto: se a tradição protestante trouxe como um dos elementos fundamentais de ruptura com o universo católico o ataque às mediaçôes santificadas, isto é, à chamada idolatria, o pentecostalismo que aqui analisamos não abandona nem a crítica à idolatria nem a prática da mediação com o mundo transcendente, mas as transforma. Com efeito, a ação divina no mundo exige, reconhecidamente, mediadores. Estes, contudo, ao serem liberados do quadro fixo da hierarquia católica podem ser reinventados na 
prática cotidiana em que o poder de Deus é chamado a intervir. Os milagres, por intermédio da ação de seus pastores, agora são constantes e publicamente valorizados na vida social. O protagonismo divino não possui mediadores fixos, consagrados na sua santidade pela hierarquia da igreja e patrimonializados como signos da catolicidade da nação. $\mathrm{O}$ caráter individualizante do protestantismo aqui se manifesta recusando as imagens mortas e a tradição religiosa e cultural que carregam. $\mathrm{O}$ corpo do pastor Marcos e as imagens produzidas em sua igreja veiculam o poder do Espírito Santo e transformam os pecadores doando-lhes, segundo suas pregações, os meios de passarem do sofrimento e da ameaça de morte a uma vida integrada na sociedade dos homens porque comprometida, balizada e protegida pela comunidade evangélica imaginada. Esta comunidade virtual é construída como algo atemporal, no encontro entre tempos e espaços distintos, reunindo o vasto grupo que se identifica e é identificado pelo pertencimento ao povo de Deus.

A comunidade virtual elaborada pelo trabalho do pastor no âmbito moral é construída também, como vimos, transformando a força em poder. Os indivíduos que se encontram submetidos às leis mundanas nesta esfera moral negativamente marca$\mathrm{da}$, controlada pelo diabo, ganham outra vida pela interferência da transcendência divina - o único e verdadeiro poder efetivo no mundo, proclamam os evangélicos.

A prática religiosa desta igreja elabora um personagem a um só tempo social e religioso, que testemunha o que seria a verdadeira transformação da pessoa - trata-se do resgatado da morte. Como personagem, revela a exemplaridade de uma trajetória: passou da iminência de morte ou de se transformar em homicida, o que lhe garante certa força, mas nenhum poder transformador - um sobrevivente, em suma, de uma guerra não declara$\mathrm{da}-$, a alguém que testemunha o poder da interferência divina e, como tal, capacitado a ter outro lugar na sociedade. Em seus testemunhos, eles, os ex-bandidos, pecadores, resgatados da morte, afirmam ter ganhado merecidamente a densidade social e moral que lhes faltava. E é deste lugar que reclamam por reconhecimento, o qual está longe de ser de natureza "puramente" religiosa. Queremos dizer com isso que os conversos exigem, no quadro de uma dinâmica social complexa, que cessem os estigmas imputados a eles, que a Bíblia que carregam e o terno que vestem sejam um sinal potente contra todas as ameaças.

Integrar-se na comunidade virtual dos evangélicos é, pois, politicamente apresentado como um convite que encerra uma condição: o cristianismo aqui se apresenta pela promessa de vida eterna, cujo caminho implica um projeto de integração social, de cidadania, nas palavras do pastor. Certamente o convite à libertação, que no caso desta igreja foi designado mais apropriadamente como alvará espiritual, não é o único apresentado às "populações de indesejáveis”. Quase todos os missionários religiosos e seculares, a bem dizer, não mencionam direitos sociais e civis a não ser no condicional. Mas isto é já outra história...

\section{Notas}

1 No Rio de Janeiro desenvolveu-se uma vasta e importante literatura sobre favela que não temos condições de explorar aqui. Cf. Caldeira (2000), Zaluar (1985, 1994 e2004), Leite (2000), Misse (1999), entre outros. Queremos no entanto destacar a relevância que teve a coletânea organizada por Machado da Silva (2008) sobre a questão atual da violência nas favelas e o trabalho de Lícia Valladares (2005) para a compreensão do caráter historicamente construído de seus moradores como membros das "classes perigosas".

2 Para uma discussão sobre secularização e modernidade no Brasil, ver Camurça (2006); Pierucci (2006a e b) e Birman (2012a e b). Para uma análise histórica do pentecostalismo no Brasil, ver Freston (1994).

3 Cf. Almeida (2010) sobre o campo religioso no Brasil atual.

4 Reportamo-nos à definição de Veena Das e Deborah Poole a propósito da noção de "margem". Elas indicam a necessidade de abandonar o modelo weberiano que opõe a razão universal, detida pelo Estado, às relaçôes violentas, próprias daqueles aos quais o Estado ainda não teria alcançado. Segundo as autoras, em vez de compreender as margens, as formas locais e pessoais de poder, as transgressões, as incivilidades como exteriores ao Estado, é preciso analisá-las como um de seus produtos. 
5 Sobre a relação entre religião e mídia, ver Vries e Weber (2001), Hoover e Lundby (1997), Zito (2008), Meyer e Pels (2003), Meyer e Moors (2006), Meyer (2009), Morgan (2005), Oosterbaan (2009), Van de Port (2011), Stolow (2010) e Machado (2009 e 2010).

6 No Rio de Janeiro desenvolveu-se uma vasta e importante literatura sobre favela que não temos condição de explorar aqui. Queremos destacar, para a finalidade deste artigo, a relevância do trabalho de Lícia Valladares (2005) para a compreensão do caráter historicamente construído das favelas como lugares de moradia das "classes perigosas".

7 Morgan enfatiza a importância de uma análise da "violência do ver" (violence of seeing) na tensão entre idolatria e iconoclastia para a compreensão da história das religiōes. Tanto estudos sobre veneração como sobre destruição de imagens podem e dever ser analisados de modo mais abrangente, tomando a imagem como um lócus de cruzamentos, onde importantes narrativas da história cultural tomam forma.

8 Sobre a relação dos evangélicos com a mídia e sua articulação com o esfacelamento das bases religiosas do projeto hegemônico que apresentava o Brasil como "maior país católico do mundo", ver Birman (2003).

9 Saez (2009) faz uma reflexão importante sobre a relação entre o culto aos santos e o culto aos mortos.

10 Keane (2007) analisa a relação da religião com os objetos a partir da questão da agência e das implicações morais advindas do sucesso e do fracasso do trabalho de purificação (nos termos de Latour, apud Keane [2007]) em separar humanos e não humanos, agentes e não agentes.

11 O pastor Marcos Pereira iniciou suas atividades com pregações no presídio da Ilha Grande em 1990. No entanto, suas ações nas penitenciárias do Rio de Janeiro ganharam destaque no período dos governos de Garotinho (1999-2002) e Rosinha (2003-2007), quando atuou como mediador em rebeliōes de prisioneiros a convite do Estado.

12 Esta descrição contempla o perfil do templo da ADUD no ano de 2010, período de realização do trabalho de campo ao qual se refere o presente texto.

13 Uma câmera mantém-se estática no meio do salão e outra permanece móvel, em mãos de um cinegrafista que permanece ao lado do púlpito, ora filmando o auditório, ora o dirigente, ora as pessoas de destaque.

14 Esta é, aliás, a definição clássica de "liminaridade", tal como proposta por Turner (1987).
15 No contexto específico do Rio de Janeiro, o termo "invasão" é usado nas ações policiais de "retomada de território", frequentes nos últimos anos como parte importante da política de "pacificação" do governo.

16 Trata-se de uma ação repetida com certa frequência pelo pastor Marcos, em geral com a presença de Waguinho, ex-pagodeiro e atual cantor gospel que acompanha o ministério da ADUD. Neste caso, é a igreja que reconquista territórios ocupados, de seu ponto de vista, pelo demônio.

17 Sobre a relação entre a agência do Espírito Santo e a apropriação espacial mediante invasões realizadas por pentecostais na Venezuela, ver Sanchez (2009).

18 " $[. .$.$] modos de comunicação que incluem não apenas$ a linguagem falada, mas meios não lingüísticos como música, dança, teatro, artes plásticas e gráficas combinadas de diversas formas" (Turner, 1987, p. 23).

19 Teixeira (2011), em seu estudo sobre histórias de vida e processos de conversão de pessoas que haviam passado pelo "mundo do crime", traz uma importante contribuição analítica acerca da relação entre "ex-bandidos" e pentecostalismo. O autor articula a problemática da sujeição criminal às representações do pentecostalismo acerca do criminoso, mas afirma ter encontrado, à época, resistência por parte do pastor para desenvolver sua pesquisa no âmbito da ADUD.

20 No vídeo Resgatados da Morte, diferentes histórias são narradas por seus protagonistas. Imagens do "resgate" são o mote do roteiro que se desdobra em testemunhos da família e do próprio "resgatado" sobre sua transformação.

21 Vale lembrar nesse sentido o artigo de Clara Mafra que destaca o caso de um ex-gerente do tráfico que realiza operações de salvamento como estas que destacamos aqui: "Cerca de um ano atrás, um missionário ficou sabendo, enquanto tratava de um ferimento de um rapaz, que o bando rival [...] iria acertar contas com ele naquela tarde [...] o missionário dirigiu-se imediatamente para a 'boca' a fim de retirar o indivíduo de lá. Com esta atitude, o missionário interferiu no andamento normal das coisas [...] na [sua visão] com aquela atitude salvou-se uma vida e, mais tarde, ganhou-se um servo de Deus" (Mafra, 1998, p. 292).

22 Ver Farias (2008).

23 "Utopias efetivamente realizadas, nas quais os posicionamentos reais, todos os outros posicionamentos reais que se podem encontrar no interior da cultura, estão ao mesmo tempo representados, contestados e inver- 
tidos, espécies de lugares que estão fora de todos os lugares, embora eles sejam efetivamente localizáveis" (Foucault, 2009, p. 415).

24 Expressão usada por Michel Agier (2008) quando associa os processos de exclusão no mundo globalizado contemporâneo à visão que se tem da população de migrantes, demandantes de asilo, moradores de periferia e favelas, habitantes de acampamentos, entre outros.

25 Uma referência importante sobre a relação entre tráfico de drogas e pentecostalismo no Rio de Janeiro é o trabalho de Vital (2009), que analisa a passagem das referências aos cultos afro-brasileiros para uma "gramática pentecostal" no meio do tráfico, o que constituiu, segundo a autora, um reequilíbrio de poder no interior do campo político e religioso local e supralocal.

26 Sobre o ideal moderno de pessoa e as práticas cristãs, ver Keane $(2006,2007)$.

27 A esse respeito, ver Almeida (2003), Meyer (1998), Birman (2003, 2011), Oosterbaan (2009), Mariz (1999), entre outros.

28 É o que foi ressaltado, por exemplo, nos estudos sobre a Igreja Universal do Reino de Deus, nos dois continentes aliás, que trazem para seus rituais fios cuja trama provê o nível de continuidade com cultos "tradicionais". Cf. Meyer (1998).

29 Vera Telles chama atenção para a presença significativa da "experiência do encarceramento" na cidade e em suas periferias, pelo fato de ser hoje "quase impossível encontrar uma família que não tenha contato e familiaridade, direta ou indireta [...], com a experiência do encarceramento" (2010, p. 120).

30 A categoria "sofrimento social" é trabalhada por Kleinman, Das e Lock (1997) como forma de destacar a dimensão sociológica daquelas experiências subjetivas resultantes de questôes políticas, econômicas e institucionais.

31 Talal Asad (1997) discute a prática de tortura no contexto policial e mostra que hoje a crueldade por parte do Estado moderno é escamoteada, executada em segredo. Com efeito, a tortura vista como crueldade nunca foi confundida historicamente com a exibição da maldade como forma de condenação e punição públicas que guardam frequentemente a condição de espetáculo.

32 Para uma discussão sobre a relação entre transcendência e imanência no pentecostalismo contemporâneo, ver Robbins (2011)
33 Kleinman, Das e Lock (1997) analisam os processos político-culturais que contribuem para uma apropriação profissional do sofrimento, processos esses que, de acordo com os autores, possuem importantes implicaçôes morais, nas quais se evidencia o "consumo do sofrimento" e suas imagens.

34 Destaca-se neste entrecruzamento midiático o trânsito confortável das imagens produzidas pela igreja em reportagens sobre o pastor (Fantástico, de 2008, e Conexão Repórter, de 2010), produzidas com imagens "gentilmente cedidas pelo pastor Marcos".

35 Mbembe (2003) propõe uma via de análise da vida social que designa como necropolítica. Ele discute como as formas contemporâneas de submissão da vida aos poderes da morte têm reconfigurado profundamente as relações entre resistência, sacrifício e terror nos espaços periféricos das cidades. O foco incide, portanto, nos poderes da morte, já que em certos casos seria insuficiente uma ênfase na perspectiva biopolítica do fazer viver. Mbembe sugere a construção de uma analítica do necropoder e de uma topografia da crueldade. Sobre este debate ver também Agier (2008) Alsayyad e Roy (2009).

36 Frase impressa no envelope de doações que foi distribuído aos fiéis durante o culto a que assistimos, assinado pela ADUD Produções.

37 Nosso foco aqui são os modos religiosos de organizar a metrópole e não, como usualmente se propõe, os modos políticos de o Estado e a sociedade organizarem o lugar da religião.

38 Desde 2004 o pastor Marcos Pereira foi proibido de entrar nos presídios do Rio de Janeiro por suspeita de ligação com a organização criminosa Comando Vermelho. As acusações contra ele até hoje não foram provadas. Atualmente, suas intervençôes ocorrem principalmente em delegacias e favelas do estado do Rio de Janeiro e em presídios do país, exceto no Rio de Janeiro.

\section{BIBLIOGRAFIA}

AGAMBEN, Giorgio. (2008), O que resta de Auschwitz. São Paulo, Boitempo.

AGIER, Michel. (2008). Gérer les indésirables: des camps de réfugiés au gouvernement humanitaire. Paris, Flammarion.

ALMEIDA, Ronaldo. (2003), "A guerra das possessões", in A. Corten, A. Oro e J. P. Dozon 
(orgs.), A Igreja Universal do Reino de Deus: os novos conquistadores da fé, São Paulo, Paulinas. . (2010), "Religião em transição", in Luiz Fernando Duarte (coord.), Antropologia: horizontes das ciências sociais no Brasil, São Paulo, Barcarolla, pp. 367-415.

ALSAYYAD, Nezar \& ROY, Ananya. (2009), "Modernidade medieval: cidadania e urbanismo na era global". Novos Estudos Cebrap, 85.

ANDERSON, Benedict. (2005), Comunidades Imaginadas: reflexōes sobre a origem e a expansão do nacionalismo. Tradução de Catarina Mira. Lisboa, Edições 70.

APPADURAI, Arjun. (1996), Modernity at large: cultural dimensions of globalization. Minneapolis/Londres, University of Minnesota Press.

ASAD, Talal. (1997), "On torture, or cruel, inhuman, and degrading treatment", in A. Kleinman, V. Das e M. Lock (eds.), Social suffering, Berkeley/Los Angeles/Londres, University of California Press.

BIRMAN, Patricia. (2003), "Imagens religiosas e projetos para o futuro", in P. Birman (org.), Religiāo e espaço público. São Paulo, Pronex/Attar. . (2011), "Formas evangélicas de viver em espaços periféricos", mimeo.

. (2012a), "O poder da fé, o milagre do poder: mediadores evangélicos e deslocamento de fronteiras sociais. Horizonte Antropológico, 18 (37).

. (2012b). "Cruzadas pela paz: práticas religiosas e projetos seculares relacionados à questão da violência no Rio de Janeiro". Religião e Sociedade, 32 (1).

CALDEIRA, Tereza Pires do Rio. (2000), Cidade de muros: crime, segregação e cidadania em São Paulo. São Paulo, Editora 34/Edusp.

CAMURÇA, Marcelo. (2006), "A realidade das religióes no Brasil no Censo do IBGE", in Faustino Teixeira e Renata Menezes (orgs.), As religiōes no Brasil: continuidades e rupturas. Petrópolis, Vozes.

DAS, Veena \& POOLE, Deborah (eds.). (2004), Anthropology in the margins of the State. Santa FélOxford, School od American Research Press/James Currey.
FARIAS, Juliana. (2008), "Da asfixia: reflexôes sobre a atuação do tráfico de drogas nas favelas cariocas", in Antonio Machado da Silva (org.), Vida sob cerco: violência e rotina nas favelas do Rio de Janeiro, Rio de Janeiro, Nova Fronteira, pp. 173-191.

FOUCAULT, Michel. (2009), "Outros espaços", in Manoel Barros da Motta (org.), Estética: literatura e pintura, musica e cinema. Tradução de Inês Autran Dourado. 2. ed. Rio de Janeiro, Forense Universitária.

FRESTON, Paul. (1994), "Breve história do pentecostalismo brasileiro", in Alberto Antonniazi et al., Nem anjos nem demônios: interpretaçôes sociológicas do pentecostalismo, Petrópolis, Vozes, pp. 67-162.

GIUMBELLI, Emerson. (2002), O fim da religiäo: dilemas da liberdade religiosa no Brasil e na França. São Paulo, Pronex/Attar.

HOOVER, Stewart \& LUNDBY, Knut. (1997), Rethinking media, religion and culture. Thousand Oaks, Sage Publications.

KEANE, Webb. (2006), "Anxious transcendence", in F. Cannel (ed.), Anthropology of Christianity, Durham/Londres, Duke University Press. (2007), Christian moderns: freedom and fetish in the mission encounter. Berkeley/ Los Angeles/Londres, University of California Press.

KLEINMAN, Arthur; Das, Veena \& Lock, Margaret (eds.). (1997), Social suffering. Berkeley/ Los Angeles/Londres, University of California Press.

LEITE, Márcia da Silva Pereira. (2000), "Entre individualismo e solidariedade: dilemas da política e da cidadania no Rio de Janeiro". Revista Brasileira de Ciências Sociais, 15 (44): 73-90.

MACHADO, Carly. (2009), "Prophecy on stage: fame and celebrities in the context of the Raelian Movement", in Birgit Meyer (ed.), Aesthetic formations: media, religion, and the senses, Nova York, Palgrave Macmillan.

(2010), "Novos movimentos religiosos, indivíduos e comunidade: sobre família, mídia e outras mediaçōes". Religião e Sociedade, 30 (2). 
MACHADO DA SILVA, Antonio (org.). (2008), Vida sob cerco: violência e rotina nas favelas do Rio de Janeiro. Rio de Janeiro, Nova Fronteira.

MAFRA, Clara. (1998), "Drogas e símbolos, redes de solidariedade em contextos de violência”, in Alba Zaluar e Marcos Alvito (orgs.), Um século de favela, Rio de Janeiro, FGV.

MBEMBE, Achille. (2003), "Necropolitics". Public Culture, 15 (1): 11-40.

MARIZ, Cecília. (1999). "A teologia da Batalha Espiritual: uma revisão da literatura”. $B I B, 47$ (10 semestre): 33-48.

MEYER, Birgit. (1998), "Make a complete break with the Past: memory and post-colonial modernity in Ghanaian discourse". Journal of Religion in Africa, 28 (3): 316-349.

(ED.). (2009), Aesthetic formations: media, religion, and the senses. Nova York, Palgrave Macmillan.

MEYER, Birgit \& MOORS, Annelies (eds.). (2006), Religion, media and the public sphere. Bloomington/Indianapolis, Indiana University Press.

MEYER, Birgit \& PELS, Peter (eds.). (2003), Magic and modernity: interfaces of revelation and concealment. Stanford, Stanford University Press.

MISSE, Michel. (1999), Malandros, marginais e vagabundos: acumulação social da violência no Rio de Janeiro. Rio de Janeiro, tese de doutorado, Instituto Universitário de Pesquisa do Estado do Rio de Janeiro - Iuperj, mimeo.

MORGAN, David. (2005), The sacred gaze: religious visual culture in theory and practice. Berkeley/Los Angeles/Londres, University of California Press.

OOSTERBAAN, Martijn. (2009), "Purity and the devil: community, media, and the body - Pentecostal adherents in a favela in Rio de Janeiro", in Birgit Meyer (ed.), Aesthetic formations: media, religion, and the senses, Nova York, Palgrave Macmillan.

PARK, Robert Ezra. (1973), A cidade: sugestôes para a investigação do comportamento humano no meio urbano, in Otávio Guilherme
Velho, O fenômeno urbano, Rio de Janeiro, Zahar.

PIERUCCI, A. Flávio. (2006a), "Religião como solvente - uma aula". Novos Estudos Cebrap, 75: 111-127.

. (2006B) "CADÊ A NOSSA DIVERSIDADE RELIGIOSA? COMENTÁRIOS AO TEXTO DE MARCELO CAMURÇA”, in Faustino Teixeira e Renata Menezes (orgs.), As religióes no Brasil: continuidades e rupturas, Petrópolis, Vozes.

ROBBINS, Joel. (2011), "Transcendência e a antropologia do cristianismo: mudança, linguagem e individualismo”. Religião e Sociedade, no prelo.

SAEZ, Oscar. (2009), "O que os santos podem fazer pela antropologia”. Religiāo e Sociedade, 29 (2): 198-219.

SÁNCHEZ, Rafael. (2009), "Seized by the spirit: the mystical foundation of squatting among pentecostals in Caraça (Venezuela) today", in B. Meyer (ed.), Aesthetic formations: media, religion, and the senses, Nova York, Palgrave Macmillan.

STOLOW, Jeremy. (2010), Orthodoxy by design: judaism, print politics, and the artscroll revolution. California, University of California Press.

TEIXEIRA, Cesar. (2011), A construção social do "ex-bandido": um estudo sobre sujeição criminal e pentecostalismo. Rio de Janeiro, 7 Letras.

TELLES, Vera. (2010), "Nas dobras do legal e do ilegal: ilegalismos e jogos de poder nas tramas da cidade". Dilemas: Revista de Estudos de Conflito e Controle Social, 2 (5-6): 97-126.

TURNER, Victor. (1987), The anthropology of performance. Nova York, paj.

VALLADARES, Licia do Prado. (2005), A invenção da favela. Rio de Janeiro, FGV.

VAN DE PORT, Mattijs. (2011), Ecstatic encounters: Bahian candomble and the quest for the really real. Amsterdam, Netherlands, Amsterdam University Press.

VITAL, Christina. (2009), Evangélicos em ação nas favelas cariocas: um estudo socioantropoló- 
gico sobre redes de proteção, tráfico de drogas e religião no Complexo de Acari. Rio de Janeiro, tese de doutorado, Universidade do Estado do Rio de Janeiro.

VRIES, Hent de \& WEBER, Samuel (eds.). (2001), Religion and media. Stanford, Stanford University Press.

ZALUAR, Alba. (1985), A máquina e a revolta. São Paulo, Brasiliense. . (1994), Condominio do diabo. Rio de Janeiro, ufrj. (2004), Integração perversa: pobreza e tráfico de drogas. Rio de Janeiro, FGV.

ZALUAR, Alba \& ALVITO, Marcos (orgs.). (1998), Um século de favela. Rio de Janeiro, FGV.

ZITO, Angela. (2008), "Religion is media”. Excerpted from Rethinking Religion 101: Critical Issues in Religious Studies, edited by Bradford Verter and Johannes Wolfart. Disponível em <http://www.uu.blymiller.com/ shaag/media.pdf $>$. 


\section{A VIOLÊNCIA DOS JUSTOS: EVANGÉLICOS, MÍDIA E PERIFERIAS DA METRÓPOLE}

\section{Patricia Birman e Carly Machado}

Palavras-chave: Pentecostalismo; Violência; Mediaçôes político-religiosas, Comunidade moral.

Na igreja Assembleia de Deus dos Últimos Dias ex-bandidos, agora missionários, são personagens centrais na constituição de circuitos simbólicos e territoriais em que criminalidade e religião se entrelaçam. Em espaços periféricos, reconfigurados por esse imaginário evangélico, os mediadores político-religiosos desta igreja buscam uma transformação redentora dos "bandidos" e dos territórios do crime. Por meio de rituais, o pastor Marcos forja uma comunidade imaginada fortemente calcada nas experiências de vida dos moradores de periferias diversas. Neste artigo, discutimos como a constituição físico-moral da pessoa resgatada por esta igreja atua sobre o sofrimento não apenas de ex-bandidos, mas de todos aqueles que se identificam com um cenário mais amplo do crime, da violência.

\section{THE VIOLENCE OF THE JUST: EVANGELICALS, MEDIA AND THE PERIPHERIES OF THE METROPOLIS}

\section{Patrícia Birman and Carly Machado}

Keywords: Pentecostalism; Violence; Psycho-religious mediations; Moral community.

In the Assembly of God of the Last Days, former bandits, now missionaries, are central personages in the constitution of symbolic and territorial circuits in which criminality and religion are intertwined. In peripheral spaces, reconfigured by such evangelical imaginary, the politico-religious mediators of that church seek a redeeming transformation of the "bandits" and the crime territories. By means of rituals, Pastor Marcos forges an imaginary community strongly modeled on the life experiences of the dwellers of different peripheries. In this article, we discuss how the physic-moral constitution of the person redeemed by this church acts upon the sufferings not only of the former bandits, but of those identified with the larger scenario of crime and violence.

\section{LA VIOLENCE DES JUSTES: ÉVANGÉLIQUES, MÉDIAS ET PÉRIPHÉRIES DE LA MÉTROPOLE}

\section{Patricia Birman et Carly Machado}

Mots-clés: Pentecôtisme; Violence; Médiations politiques et religieuses; Communauté morale.

Dans l'église de l'Assemblée de Dieux des Derniers Jours, des ex-bandits, convertis en missionnaires, sont les personnages centraux de la constitution de circuits symboliques et territoriaux dans lesquels la criminalité et la religion s'entrelacent. Dans des espaces périphériques, reconfigurés par cet imaginaire évangélique, les médiateurs politico-religieux de cette église cherchent une transformation rédemptrice des "bandits" et des territoires du crime. Grâce à des rituels, le pasteur Marcos forge une communauté imaginaire fortement ancrée sur les expériences de vie des habitants des diverses périphéries. Dans cet article nous discutons de quelle façon la constitution physique et morale de la personne récupérée par cette église agit sur la souffrance d'anciens bandits et de tous ceux qui s'identifient au scénario plus ample du crime et de la violence. 